\section{(6) OPEN ACCESS}

\title{
Head injury from falls in children younger than 6 years of age
}

\author{
P Burrows, ${ }^{1}$ L Trefan, ${ }^{1}$ R Houston, ${ }^{2}$ J Hughes, ${ }^{1}$ G Pearson, ${ }^{3}$ R J Edwards, ${ }^{4}$ P Hyde, ${ }^{5}$ \\ I Maconochie, ${ }^{6}$ R C Parslow, ${ }^{7}$ A M Kemp ${ }^{1}$
}

- Additional material is published online only. To view please visit the journal online (http://dx.doi.org/10.1136/ archdischild-2014-307119).

For numbered affiliations see end of article.

\section{Correspondence to} Dr Alison Kemp, Institute of Primary Care and Public Health, Cardiff School of Medicine, Neuadd Meirionnydd, Heath Park, Cardiff, Wales CF14 4YS, UK; KempAM@cf.ac.uk

Received 25 July 2014 Revised 26 March 2015 Accepted 13 April 2015 Published Online First 21 August 2015

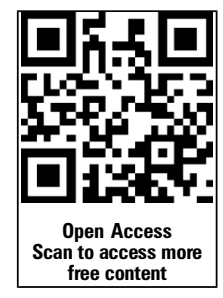

CrossMark

To cite: Burrows $P$,

Trefan L, Houston $\mathrm{R}$, et al.

Arch Dis Child

2015; 100:1032-1037.

\section{ABSTRACT}

The risk of serious head injury (HI) from a fall in a young child is ill defined. The relationship between the object fallen from and prevalence of intracranial injury (ICI) or skull fracture is described.

Method Cross-sectional study of HIs from falls in children ( $<6$ years) admitted to UK hospitals, analysed according to the object fallen from and associated Glasgow Coma Score (GCS) or alert, voice, pain, unresponsive (AVPU) and CT scan results.

Results Of 1775 cases ascertained (median age 18 months, $54.7 \%$ boys), $87 \%$ (1552) had a GCS=15/ AVPU=alert. 19.3\% (342) had a CT scan: 32\% (110/342) were abnormal; equivalent to $5.9 \%$ of the overall population, $16.9 \%$ (58) had isolated skull fractures and $13.7 \%$ (47) had ICI (49\% (23/47) had an associated skull fracture). The prevalence of $\mathrm{ICl}$ increased with neurological compromise; however, $12 \%$ of children with a GCS $=15 /$ $A V P U=a l e r t$ had ICI. When compared to falls from standing, falls from a person's arms (233 children (mean age 1 year)) had a significant relative OR for a skull fracture/lCl of 6.94 ( $95 \%$ Cl 3.54 to 13.6), falls from a building (eg, window or attic) (mean age 3 years) OR 6.84 $(95 \% \mathrm{Cl} 2.65$ to 17.6$)$ and from an infant or child product (mean age 21 months) OR $2.75(95 \% \mathrm{Cl} 1.36$ to 5.65$)$.

Conclusions Most HIs from a fall in these children admitted to hospital were minor. Infants, dropped from a carer's arms, those who fell from infant products, a window, wall or from an attic had the greatest chance of $\mathrm{ICl}$ or skull fracture. These data inform prevention and the assessment of the likelihood of serious injury when the object fallen from is known.

\section{INTRODUCTION}

Head injury (HI) from a fall is a leading cause of hospital attendance for young children. ${ }^{1}$ The majority of these head injuries are minor; however, a small proportion result in intracranial injury (ICI) to the brain or surrounding extra-axial structures. ${ }^{1}$ In 2011, Hospital Episode Statistics recorded 50719 finished hospital consultations for children age 0-14 who fell (International Classification of Diseases, 10th revision W00-W19). ${ }^{2}$ Little is known about the characteristics of falls that have the potential to cause skull fractures or ICI and potential neuropsychological morbidity. ${ }^{3}$

The estimated proportion of childhood HIs caused by falls varies from $19 \%{ }^{4}$ to $89 \%{ }^{5}$ with many studies reporting figures between $50 \%$ and $70 \%{ }^{6-8}$ The prevalence decreases with age, with infants ( $<12$ months of age) and very young children at the greatest risk. ${ }^{69}$ However, studies are based upon small sample sizes and broad age ranges.

\section{What is already known on this topic?}

Falls are a common mechanism in young children admitted to hospital with head injury.

- Most are minor head injuries but can be associated with morbidity from post-concussion syndrome.

- The likelihood of cranial or intracranial damage from different fall mechanisms is ill defined.

\section{What this study adds?}

- Abnormal CT scans were identified in $5.9 \%$ of the children who had sustained head injury from a fall.

- The highest risk mechanism of fall for acquiring skull fracture or intracranial injury is an infant who is dropped from a carer's arms.

- These data have the potential to inform prevention to reduce the number of infants and young children who sustain head injuries from falls.

They often report falls from the 'same level' or from 'an estimated height'. Some studies with a biomechanical focus do highlight the objects and furniture types involved in falls; ${ }^{10}{ }^{11}$ however, small sample sizes prevent generalisation of these results.

There are two schools of thought about the significance of short falls: ${ }^{12}$ first, they rarely cause fatal $\mathrm{HI}^{13}$ and second, they have the potential to do so. ${ }^{14}$

The Confidential Enquiry into Head Injury in Childhood was the principal project within the Centre for Maternal and Child Enquires (CMACE) in 2009. Data were collected from 90\% of hospitals in England, Wales, Northern Ireland and the Channel Islands on children treated or observed in hospital inpatient areas. This large dataset provided the opportunity to describe the object fallen from, the neurophysiological status and CT scan findings in children younger than 6 years.

\section{METHODS}

All cases described as falls were extracted from the CMACE dataset of children younger than 6 years of age, admitted to hospital or who died at the scene or en route to hospital as a direct result of an HI between September 2009 and February 2010. Children admitted because of superficial or facial 
injuries were not included in the original dataset. Cases with insufficient data regarding the mechanism of injury, readmissions and those that were referred to social services for suspected physical abuse where there was uncertainty around the mechanism of injury were excluded. Cases that met clinical guidelines for a CT $\operatorname{scan}^{15}$ but where a CT scan had not been done were also excluded as we could not confirm the outcome.

Data were collected for this cross-sectional study monthly in each hospital using predefined proformas (see online supplementary file 1) by a designated local coordinator. Data from completed forms were entered onto a secure database and duplicate cases were excluded.

The child was classed as a hospital admission if they were admitted to a hospital inpatient setting for $4 \mathrm{~h}$ or more. The descriptions of falls were recoded using The European Union Injury Database Coding Manual. ${ }^{16}$ Incident place was coded according to home/private address, school/nursery, public highway/road/street/motorway other, unknown. Mechanism of injury: Falls were recoded as 'Falls from standing or sitting' and 'Falls from a height' and subcategorised according to falls from building, building component or related fitting, from person's arms, downstairs, from furniture, infant or child product or other. Object fallen from were initially categorised in accordance with the coding manual. These categories were then condensed down into six larger categories (see online supplementary file 2) with relevant subdivisions.

The Glasgow Coma Score (GCS) recorded from the emergency department was the primary indicator of neurological status. When missing, the alert, voice, pain, unresponsive (AVPU) scores ${ }^{17}$ were used. These data were combined to create four categories-'GCS=15/alert,' 'GCS =13-14' 'GCS=9-12/ response to voice' and 'GCS $\leq 8$ / response to pain or unresponsive'-as proposed by Mackay et al. ${ }^{18}$ (While Mackay et al refer to children older than 5 years, this was the best equivalence study available.) CT scan results were categorised as normal (no abnormality reported on CT scan), isolated skull fracture or intracranial injury (ICI) (injury to the brain or extra-axial structures) with or without skull fracture. Structural anomalies congenital defects and soft tissue injuries were combined with CT normal group. Two coders independently reviewed CT scan results and agreed the categorisation of injury mechanism and objects fallen from.

HIs were classified as 'minor' if a CT scan was performed with a 'normal' result or no CT was performed but the GCS/ AVPU score was GCS $=15 /$ alert.

\section{Analysis of the dataset}

A descriptive analysis used proportions with 95\% CIs. The logistic regression analysis (IBM SPSS V.20) was used to calculate the relative odds of sustaining a skull fracture or ICI from each mechanism to a fall from sitting or standing. A general model, including possible influencing covariates, namely mechanism of injury gender, age in years, was applied to the data and by a stepwise approach the statistically non-significant factors were removed from the model. To compare the accuracy of fit of the models, the software calculated fit statistics were used: (model) $\chi^{2},-2$ log-likelihood, overall percentage-the overall per cent of cases that are correctly predicted by the model (IBM SPSS V.20). The best-fitting logistic model results are expressed as ORs, with 95\% CIs.

\section{RESULTS}

The original dataset included 5700 children (ages of $0-15$ ). Of these, 60\% (3423) were <6 years, 76.9\% (2634) of whom presented following a fall. In total, 153 cases referred to social services with suspected physical abuse, 11 cases that met criteria for a CT but CT scan was not done and 695 cases with insufficient data regarding the mechanism of injury were excluded. This latter group of cases had the same distribution of age, gender, GCS/AVPU and abnormal CT scan results as the remaining 1775 cases available for analysis (figure 1).

The median age of the children was 18 months (IQR 30 months). There was an inverse relationship between age and number of children who sustained HI from a fall (table 1). A slightly greater proportion of HIs occurred in boys $(54.7 \%$, $\mathrm{n}=971$ ) than in girls.

\section{Injury severity}

A total of 1659 children had a GCS (1245) or an AVPU (414) recorded. Of the total population, $87 \%(1552 / 1775)$ had a GCS of 15 or were alert on AVPU. The length of stay was recorded for 1735 children. The median number of nights admitted was 1 (1005 children), 100 children were admitted for 2-4 nights, 8 for 5-7 days and 4 for more than a week, 616 were observed and sent home the same day. Two children died from their injuries.

CT scan was performed in $19.3 \%$ (342). A significantly greater proportion of children aged $3-5$ years $(26.6 \%$ (95\% CI $22.9 \%$ to $30.6 \%)$ ) than children younger than 3 years $(16.5 \%$ (95\% CI $14.5 \%$ to $18.6 \%$ )) had a CT scan (table 2). Overall $68 \%(233 / 342)$ had a normal CT, 16.9\% (58) had isolated skull fractures, $13.7 \%$ (47) had ICI (49\% (23) of whom had an associated skull fracture), and 4 were reported as abnormal but details were not given (tables 1 and 2). Children younger than a year had the greatest proportion of abnormal CT scans of $58 \%$ $(58 / 100), 74.1 \%(43 / 58)$ of which were in children younger than 6 months of age. While the proportion of children with ICI increased with neurological compromise reflected by increased GCS/AVPU, ICI was identified in 12\% (31/260) of children with a GCS $=15 / \mathrm{AVPU}=$ alert who had a CT scan (table 2).

Also, 62 of the 81 skull fractures were simple linear fractures (41 parietal/temporal, 6 frontal, 11 occipital, 2 basal, 2 location not recorded), 13 were complex fractures (5 bilateral and 7 depressed fractures, 1 multiple). In six cases, neither the site nor type was specified. There was no difference between the distribution of fracture type or site between the children who had coexisting ICI. Twenty-three children had fractures with ICI, in 22 there were underlying extra-axial haemorrhage, contusions

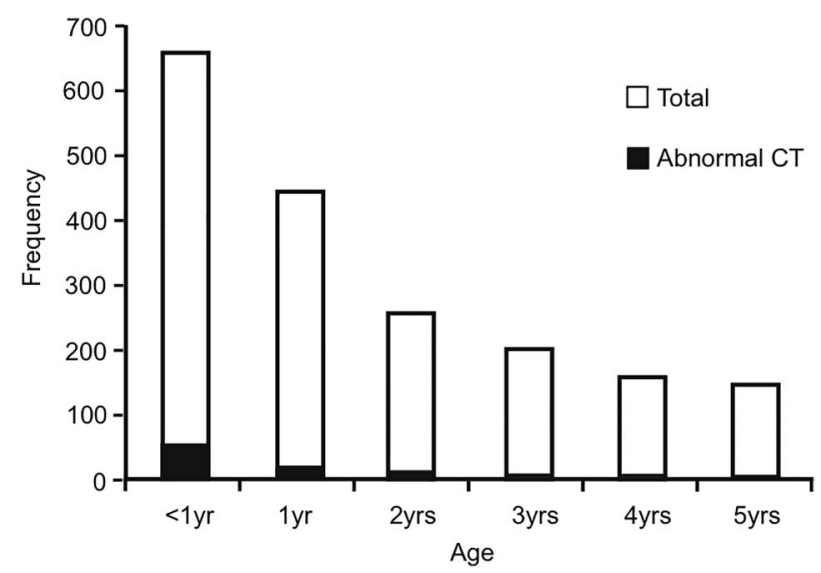

Figure 1 Age of 1775 children who were admitted to hospital after a head injury from a fall. 
Table 1 Number and proportion of children who had a CT scan and CT findings by age

\begin{tabular}{|c|c|c|c|c|c|c|}
\hline $\begin{array}{l}\text { Children } \\
\text { age (years) }\end{array}$ & $\begin{array}{l}\text { No. children who } \\
\text { had CT scan }\end{array}$ & Minor $\mathrm{HI}^{*}$ & $\begin{array}{l}\text { Isolated skull } \\
\text { fracture }\end{array}$ & $\begin{array}{l}\text { ICI with/without } \\
\text { skull fracture }\end{array}$ & $\begin{array}{l}\text { CT scan stated as abnormal } \\
\text { but no results given }\end{array}$ & Total \\
\hline$<1$ & $\begin{array}{l}100 \\
16.4 \%\end{array}$ & $\begin{array}{l}545 \\
90.4 \%\end{array}$ & $\begin{array}{l}36 \\
6.0 \%\end{array}$ & $\begin{array}{l}20 \\
3.3 \%\end{array}$ & $\begin{array}{l}2 \\
0.3 \%\end{array}$ & $\begin{array}{l}603 \\
34 \%\end{array}$ \\
\hline 1 & $\begin{array}{l}69 \\
16.1 \%\end{array}$ & $\begin{array}{l}408 \\
95.1 \%\end{array}$ & $\begin{array}{l}14 \\
3.3 \%\end{array}$ & $\begin{array}{l}5 \dagger \\
1.2 \%\end{array}$ & $\begin{array}{l}1 \\
0.2 \%\end{array}$ & $\begin{array}{l}429 \dagger \\
24.2 \%\end{array}$ \\
\hline 2 & $\begin{array}{l}42 \\
16.8 \%\end{array}$ & $\begin{array}{l}239 \\
95.6 \%\end{array}$ & $\begin{array}{l}3 \\
1.2 \%\end{array}$ & $\begin{array}{l}7 \\
2.8 \%\end{array}$ & $\begin{array}{l}1 \\
0.4 \%\end{array}$ & $\begin{array}{l}250 \\
14.1 \% \%\end{array}$ \\
\hline 3 & $\begin{array}{l}50 \\
25.1 \%\end{array}$ & $\begin{array}{l}192 \\
96.5 \%\end{array}$ & $\begin{array}{l}2 \\
1.0 \%\end{array}$ & $\begin{array}{l}5 \\
2.5 \%\end{array}$ & $\begin{array}{l}0 \\
0.0 \%\end{array}$ & $\begin{array}{l}199 \\
11.2 \%\end{array}$ \\
\hline 4 & $\begin{array}{l}41 \\
27.0 \%\end{array}$ & $\begin{array}{l}145 \\
95.4 \%\end{array}$ & $\begin{array}{l}3 \\
2.0 \%\end{array}$ & $\begin{array}{l}3 \\
2.0 \%\end{array}$ & $\begin{array}{l}1 \\
0.7 \%\end{array}$ & $\begin{array}{l}152 \\
8.6 \%\end{array}$ \\
\hline 5 & $\begin{array}{l}40 \\
28.2 \%\end{array}$ & $\begin{array}{l}135 \\
95.1 \%\end{array}$ & $\begin{array}{l}0 \\
0.0 \%\end{array}$ & $\begin{array}{l}7 \\
4.9 \%\end{array}$ & $\begin{array}{l}0 \\
0.0 \%\end{array}$ & $\begin{array}{l}142 \\
8.0 \%\end{array}$ \\
\hline Total & $\begin{array}{l}342 \\
19.3 \%\end{array}$ & $\begin{array}{l}1664 \\
93.7 \%\end{array}$ & $\begin{array}{l}58 \\
3.3 \%\end{array}$ & $\begin{array}{l}47 \\
2.6 \%\end{array}$ & $\begin{array}{l}4 \\
0.3 \%\end{array}$ & $\begin{array}{l}1775 \\
100.0 \%\end{array}$ \\
\hline
\end{tabular}

* Minor head injury defined when a CT scan was performed with a 'normal' result or no CT was performed but the GCS/AVPU score was GCS=15/alert.

tTwo 1 year olds died, one died before having a CT scan and one had ICI on CT.

AVPU, alert, voice, pain, unresponsive; GCS, Glasgow Coma Score; HI, head injury; ICl, intracranial injury.

were described in 2 cases and cerebral oedema in 1 . In the 24 children with ICI but no skull fractures, the ICI included contusions (5), intracranial haemorrhage (3), extra-axial haemorrhage (15) and cerebral oedema (1).

\section{Characteristics of the causal event}

The majority $(74.1 \%(1316 / 1775))$ of HIs occurred in the home. Falling from a height accounted for 74.5\% (1322/1775). Children who fell from a height were more likely to sustain skull fractures or ICI than those who fell from standing $(7.4 \%$ (98/1322) vs $2.7 \%(12 / 453)$ ). The calculated relative OR of this relationship was 2.9 (95\% CI 1.6 to 5.4). There was a relationship between the age of the children and the mechanism of injury; young babies fell or were dropped from a carer's arms, toddlers who fell down the stairs or from furniture had a median of 18 months, 1 year olds fell from an infant product while the older children fell from standing or from walls, windows, shopping trolleys, and so on (table 3).

The three mechanisms with the greatest proportions of abnormal CT were falls from (1) a person's arms, (2) building or building component (11 from a wall, 19 from window, 6 from attic, 6 balcony/banister/gallery/stage, 6 from bathroom furnishings or gate, 3 from patio) and (3) an infant or child product.
Stepwise elimination of co-covariates in the logistic regression model resulted in only the mechanism of injury remaining in the model. The relative ORs for sustaining a skull fracture or ICI were significantly greater than a fall from standing or sitting, namely 6.94 (95\% CI 3.54 to 13.6$), 6.84$ (95\% CI 2.65 to 17.6) and 2.75 (95\% CI 1.36 to 5.65), respectively (table 3 ). A child who fell from a carer's arms down the stairs had a greater chance $(23.3 \%$ (95\% CI $13.2 \%$ to $37.8 \%$ ) (10/43)) of sustaining a skull fracture or ICI compared with those who were dropped on to the floor (14.2\% (95\% CI $10 \%$ to $19.9 \%$ ) (27/190)).

Figure 2 outlines the reported objects that 1775 children had fallen from. With the exception of falls from a carer's arms, from a building or an infant child product, there were no significant statistical differences in the proportion of abnormal CT findings among any of the other categories.

\section{DISCUSSION}

The greatest proportion of the children who were admitted to hospital following an HI from a fall were younger than 1 year. One-fifth of the children had a CT scan to confirm or exclude ICI. One-third of which had an abnormality reported, equivalent to $5.9 \%$ of the overall population studied. The most

Table 2 CT outcome for 342 children according to GCS/AVPU score

\begin{tabular}{|c|c|c|c|c|c|}
\hline & CT: normal & Isolated skull fracture & $\begin{array}{l}\text { ICl with/without } \\
\text { skull fracture }\end{array}$ & $\begin{array}{l}\text { CT scan stated to be } \\
\text { abnormal but no results given }\end{array}$ & Total \\
\hline GCS 1 5/AVPU $=A$ & $\begin{array}{l}180 \\
69.2 \%\end{array}$ & $\begin{array}{l}45 \\
17.3 \%\end{array}$ & $\begin{array}{l}31 \\
11.9 \%\end{array}$ & $\begin{array}{l}4 \\
1.5 \%\end{array}$ & 260 \\
\hline GCS 13-14 & $\begin{array}{l}29 \\
69.0 \%\end{array}$ & $\begin{array}{l}7 \\
16.7 \%\end{array}$ & $\begin{array}{l}6 \\
14.3 \%\end{array}$ & $\begin{array}{l}0 \\
0.0 \%\end{array}$ & 42 \\
\hline GCS 9-12/AVPU=V & $\begin{array}{l}10 \\
66.7 \%\end{array}$ & $\begin{array}{l}1 \\
6.7 \%\end{array}$ & $\begin{array}{l}4 \\
26.7 \%\end{array}$ & $\begin{array}{l}0 \\
0.0 \%\end{array}$ & 15 \\
\hline GCS 8 or less/AVPU P or $U$ & $\begin{array}{l}4 \\
40.0 \%\end{array}$ & $\begin{array}{l}1 \\
10.0 \%\end{array}$ & $\begin{array}{l}5 \\
50.0 \%\end{array}$ & $\begin{array}{l}0 \\
0.0 \%\end{array}$ & 10 \\
\hline Missing & $\begin{array}{l}10 \\
66.7 \%\end{array}$ & $\begin{array}{l}4 \\
26.7 \%\end{array}$ & $\begin{array}{l}1 \\
6.7 \%\end{array}$ & $\begin{array}{l}0 \\
0.0 \%\end{array}$ & 15 \\
\hline Total & $\begin{array}{l}233 \\
68.1 \%\end{array}$ & $\begin{array}{l}58 \\
17.0 \%\end{array}$ & $\begin{array}{l}47 \\
13.7 \%\end{array}$ & $\begin{array}{l}4 \\
1.2 \%\end{array}$ & 342 \\
\hline
\end{tabular}

AVPU, alert, voice, pain, unresponsive; GCS, Glasgow Coma Score; ICl, intracranial injury. 
Table 3 CT outcome by mechanism with relative $95 \% \mathrm{Cl}$ of sustaining a skull fracture or intracranial injury (ICI) from each mechanism compared with a fall from sitting or standing

\begin{tabular}{|c|c|c|c|c|c|c|c|c|}
\hline Mechanism & $\begin{array}{l}\text { Median age } \\
\text { years (IQR) }\end{array}$ & CT: normal & $\begin{array}{l}\text { CT: skull } \\
\text { fracture }\end{array}$ & $\begin{array}{l}\text { CT: ICI with/ } \\
\text { without skull } \\
\text { fracture }\end{array}$ & $\begin{array}{l}\text { CT: abnormal } \\
\text { scan/died }\end{array}$ & Total & $\begin{array}{l}\text { Odds ratios of skull } \\
\text { fracture or ICI to fall } \\
\text { from standing/sitting }\end{array}$ & p Value \\
\hline Persons arms & $0.3(1.1)$ & $196(84.1 \%)$ & $21(9 \%)$ & $15(6.4 \%)$ & $1(0.4 \%)$ & 233 & 6.94 (3.54 to 13.6) & $<0.001$ \\
\hline Building, building component or related fitting & $3.2(2.6)$ & $43(84.3 \%)$ & $2(3.9 \%)$ & $5(9.8 \%)$ & $1(2 \%)$ & 51 & $6.84(2.65$ to 17.6$)$ & $<0.001$ \\
\hline Other & $3.3(2.5)$ & $52(92.9 \%)$ & $2(3.6 \%)$ & $1(1.8 \%)$ & $1(1.8 \%)$ & 56 & $2.83(0.89$ to 9.09$)$ & 0.081 \\
\hline Infant or child product & $0.9(2.8)$ & $334(93 \%)$ & $17(4.7 \%)$ & $8(2.2 \%)$ & 0 & 359 & 2.75 (1.36 to 5.56$)$ & 0.005 \\
\hline Furniture & $1.5(1.8)$ & $388(95.8 \%)$ & $8(2 \%)$ & $7(1.7 \%)$ & $2(0.5 \%)$ & 405 & 1.61 (0.76 to 3.41$)$ & 0.214 \\
\hline Stairs & $1.5(1.3)$ & $211(96.8 \%)$ & $2(0.9 \%)$ & $5(2.3 \%)$ & 0 & 218 & $1.22(0.47$ to 3.14$)$ & 0.682 \\
\hline Standing/sitting & $2.4(2.8)$ & $441(97.4 \%)$ & $6(1.3 \%)$ & $6(1.3 \%)$ & 0 & 453 & & \\
\hline Total & & $1665(93.8 \%)$ & $58(3.3 \%)$ & $47(2.6 \%)$ & $5(0.3 \%)$ & 1775 & & \\
\hline
\end{tabular}

Infant product included cot, Moses basket, high chair or pram.

Building or building component included wall, window attic, balcony/banister/gallery/stage, bathroom furnishings, gate, patio.

common abnormal finding was a skull fracture, most commonly a simple linear parietal fracture, a proportion (1 in 4) of these had an underlying extra-axial haemorrhage. Few children sustained an ICI without skull fracture. These findings are similar to those of Dietrich et $a l^{19}$ and to a recent publication by Thomas $e t a l^{20}$ for children younger than 2 years old. The latter study identified 'isolated skull fractures' in $19.5 \%$ of children who had neuroimaging for head injuries and focal intracranial haemorrhage in $15.4 \%$. Although the study included all mechanisms of injury, $82 \%$ of the series were from falls.

The highest rate of abnormal CT scans was evident in infants who fell from a parent's arms, a finding consistent with other studies. $^{5} 2122$ The likelihood of an abnormal CT scan was greater for children dropped on the stairs compared with those dropped on to the floor. By contrast, falls down stairs, which were one of the most common reasons for hospital admission, resulted in a low prevalence of skull fracture or ICI.
The strength of this study is the large national dataset and representative sample. The data were limited to hospital admissions and are likely to be biased by injury severity, clinical decisions to admit cases and variation in admission policy and facilities across the UK. While there were clear national HI guidelines in place at the time of the study, ${ }^{15}$ adherence to guidelines varied and results could only be based on the CT findings according to the level of investigations undertaken. The study does not include the many children who were assessed in the emergency department and discharged home. Children referred to social services were excluded due to uncertainty about mechanism, some of which may have been genuine falls once child protection investigations were completed, but this information was not available to us. Equally it is possible that the dataset includes unrecognised cases of physical abuse. Data were collected over a 6-month winter period and are likely to have missed the summer peak incidence or seasonal variation in injury type. ${ }^{4}$
Figure 2 Object fallen from for 1775 children admitted to hospital with a head injury from a fall.

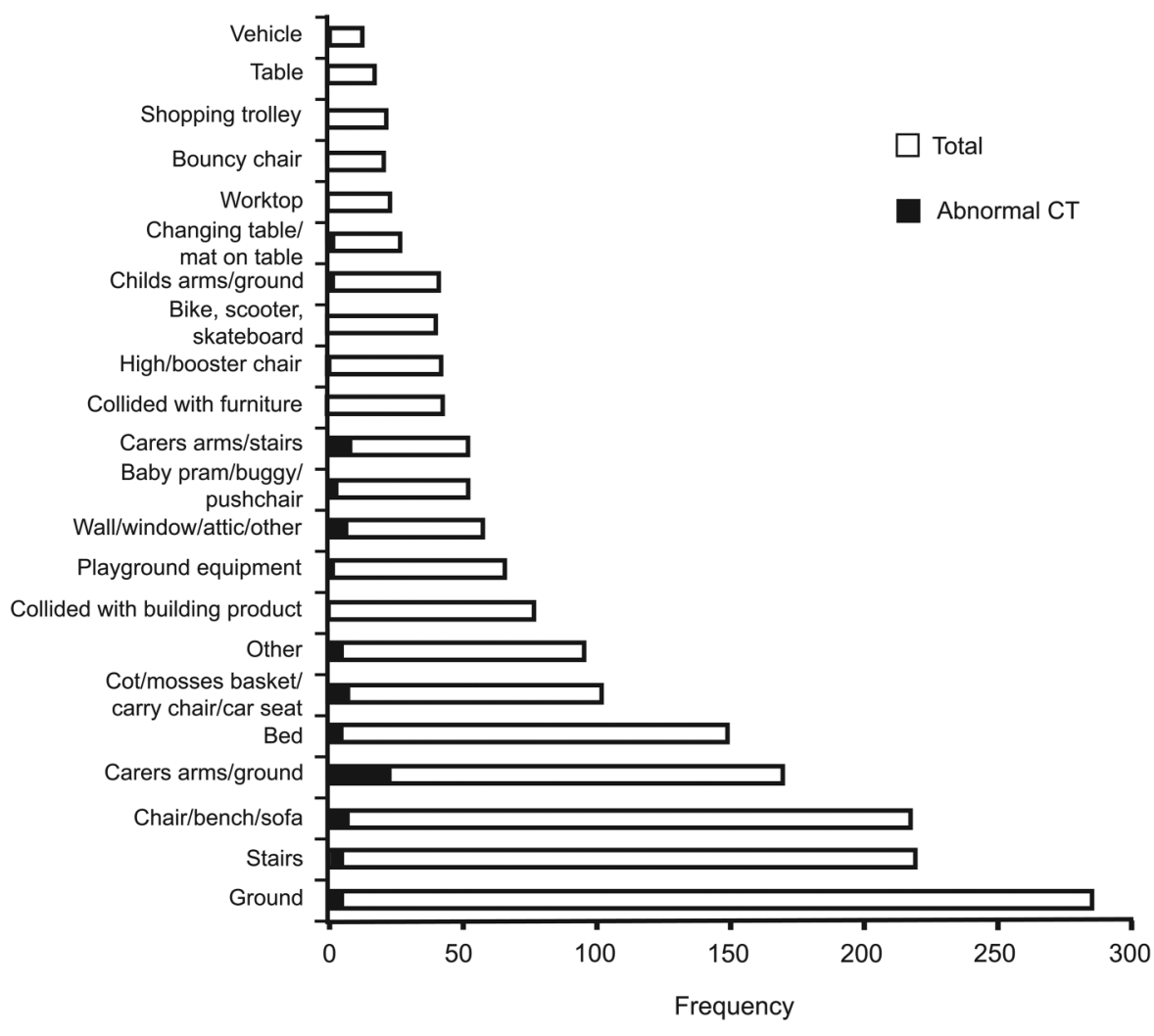


Much of the information processed and coded was written in free text, creating an element of subjectivity when categorising data. The data had been collected from $>200$ hospitals, and the quality of data entry varied. However, after exclusion of cases with poor data quality, we are confident that the dataset represents a cross section of falls in preschool children who were admitted to hospital. Although the Injury Database manual was used as a coding standard for consistency, the manual is not designed specifically for falls and was thus adapted for the population studied to include some of the emergent categories.

The increased likelihood of a skull fracture or ICI from a fall from height compared with falling from standing height was unsurprising. The height of a fall in this study was estimated in terms of the nature of the item fallen from, and this is frequently all that the clinician has to inform a clinical assessment when assessing the likelihood of cranial or intracranial structural damage.

Estimating a fall height threshold for serious $\mathrm{HI}$ is a debated topic. $^{10} 132324$ In 1991, Williams described how infants who fell from $<10 \mathrm{ft}(3 \mathrm{~m})$ were unlikely to sustain serious injuries (intracranial haemorrhages, cerebral oedema, depressed skull fractures and compound or comminuted fractures), ${ }^{23}$ while in 2008 Chadwick et al ${ }^{13}$ published a systematic review estimating a mortality rate of $<0.48$ deaths per one million children in the USA for children involved in short falls of $<3 \mathrm{ft}(<1 \mathrm{~m})$. In 2012, Ibrahim et $a l^{10}$ acknowledged that falls from a greater height could result in incrementally more serious injury but suggested that there are multiple factors to consider such as the angle of the fall, impact and landing position of the child (all beyond the scope of this study). Although we were unable to make height estimates, our results show a lower proportion of skull fractures or ICI after a fall from standing or from lowheight furniture than from falls from windows and other building components, or from a carer's arms.

Most infant falls are short vertical falls; ${ }^{22}$ however, being dropped may result in a child being released at an angle causing a non-linear fall and rapid angular deceleration on impact with the ground. ${ }^{25}$ The biomechanics involved when a child that is dropped down the stairs is complex. We hypothesise that the height of the initial fall before contact with the stairs increases the momentum with which the child continues to tumble down the stairs, increasing the complexity of the fall and the likelihood of sustaining a skull fracture or ICI. The proportion of children who sustain a skull fracture or ICI after falling down the stairs without being dropped was considerably lower $(3.4 \%$ vs $26.2 \%$ ). This mechanism has been described as a series of short falls between each individual step. ${ }^{26}$ There is a culture of anxiety concerning children falling down stairs. A retrospective study estimates that a child under the age of 5 is seen every six minutes for a stair-related fall in US emergency departments. ${ }^{27}$

This study extends our understanding of $\mathrm{HI}$ from falls and the risk of skull fracture or ICI given the age of the child and item fallen from. It identifies the dangers of dropping children while confirming that low height falls, including simple stair falls, rarely cause impaired consciousness, skull fractures or ICI. The findings have the potential to inform HI clinical decision rules about falls that warrant a CT scan. Currently, this varies from a fall of $3 \mathrm{ft}$ or more or five stairs (Canadian Assessment of Tomography for Childhood Head Injury), ${ }^{28}$ falls that exceed $0.9 \mathrm{~m}$ for children younger than 2 years or $>1.5 \mathrm{~m}(5 \mathrm{ft})$ for older children (Pediatric Emergency Care Applied Research Network) ${ }^{1}$ to falls that exceed $3 \mathrm{~m}$ (Children's Head Injury Algorithm for the Prediction of Important Clinical Events). ${ }^{29}$ Child protection specialists can apply the findings to inform decisions about the plausibility of injury explanations when assessing infants and young children with suspected physical abuse. Prevention initiatives should stress the importance of carrying children safely, particularly while going up and downstairs.

\section{Author affiliations}

${ }^{1}$ Institute of Primary Care and Public Health, Cardiff School of Medicine, Cardiff,

Wales, UK

${ }^{2}$ Placements Manager at Kids Company, London, UK

${ }^{3}$ Department of Anaesthesia and Intensive Care, University of Birmingham

${ }^{4}$ Department of Neurosurgery, Bristol Hospital for Children, Bristol, UK

${ }^{5}$ Paediatric Intensive Care Unit, Southampton Childrens Hospital, Southampton, UK

${ }^{6}$ National Institute for Health Research (NIHR) Biomedical Research Centre based at Imperial College Healthcare NHS Trust and Imperial College London

${ }^{7}$ Division of Epidemiology and Biostatistics, Leeds Institute of Genetics, Health and Therapeutics (LIGHT), University of Leeds, Leeds, UK

\section{Twitter Follow Richard Edwards at @paedneurosurg}

Acknowledgements This project/audit is commissioned by the Healthcare Quality Improvement Partnership (HQIP) as part of the National Clinical Audit and Patient Outcomes Programme (NCAPOP). This is one of a series of forthcoming publications using the study data.

Collaborators Additional members of the original CMACE Head Injury External advisory group: Professor Robert Tasker, Paediatrics, University of Cambridge, Dr Rosemary Arthur Consultant Paediatric Radiologist Leeds (British Society Paediatric Radiology), Dr Fiona Lecky: Research Director TARN, Senior Lecturer, Honorary Consultant Emergency Medicine Manchester, Dr Fiona Moore: Medical Director London Ambulance Service, Dr Kevin Moore: Director PICU Birmingham Children's Hospital. Lisa Turan: Chief Executive Child Brain Injury Trust, Girkamal Virdi: Assistant Head of Clinical and Audit Research London Ambulance Service, Mark Woolcock: Emergency Medical Practitioner and Emergency Specialist Service South Western Ambulance Service NHS Foundation Trust, UK.

Contributors PB undertook this project as an intercalated medical student when completing his BSC in Public Health. LT undertook and advised upon the statistical analysis. RH designed the original data collection tools, supervised data collection, cleaning and data entry of the data collected within the original confidential enquiry of head injury (CMACE). JH gave supervisory advice to PB, advised on biomechanics and participated in study design and analysis. GP was the director of the CMACE confidential enquiry and supervised the design and running of the project and has been involved in editing his manuscript. RJE, PH, IM and RCP were all members of the project Independent Advisory Board and gave advice and editorial supervision at regular intervals during the study analysis. AMK supervised the student project, coordinated the study writing, checked and edited the manuscript, agreed the concept and methodology of this particular analysis.

Funding Health Quality Improvement Partnership.

Competing interests IM is supported by the National Institute for Health Research (NIHR) Biomedical Research Centre based at Imperial College Healthcare NHS Trust and Imperial College London.

Patient consent CMACE obtained Section 251 approval to gather patient information without consent.

Ethics approval The project was approved by the Central Manchester Research Ethics Committee. R\&D or clinical governance approvals were obtained from all participating hospitals. These approvals were renewed when the project was transferred to Cardiff University for analysis (Ref 09/H1008/74) July 2012.

Provenance and peer review Not commissioned; externally peer reviewed.

Data sharing statement The data that informs this study is an anonymised national dataset and is available upon request for individuals who have a worthy cause to analyse as long as the rationale fits with the ethical approval and Section 251 requirements. We would consult with such bodies as necessary.

Open Access This is an Open Access article distributed in accordance with the Creative Commons Attribution Non Commercial (CC BY-NC 4.0) license, which permits others to distribute, remix, adapt, build upon this work non-commercially, and license their derivative works on different terms, provided the original work is properly cited and the use is non-commercial. See: http://creativecommons.org/ licenses/by-nc/4.0/

\section{REFERENCES}

1 Kuppermann N, Holmes JF, Dayan PS, et al. Identification of children at very low risk of clinically-important brain injuries after head trauma: a prospective cohort study. Lancet 2009;374:1160-70. 
2 Statistics HE. Admitted Patient Care, England, 2011-12: External causes 1 November 2012 ed. 2012.

3 Ewing-Cobbs L, Fletcher JM, Levin HS, et al. Longitudinal neuropsychological outcome in infants and preschoolers with traumatic brain injury. J Int Neuropsychol Soc 1997;3:581-91.

4 Parslow RC, Morris KP, Tasker RC, et al, Group UPTBISS. Epidemiology of traumatic brain injury in children receiving intensive care in the UK. Arch Dis Child 2005;90:1182-7.

5 Crowe LM, Catroppa C, Anderson V, et al. Head injuries in children under 3 years. Injury 2012;43:2141-5.

6 Kraus JF, Rock A, Hemyari P. Brain injuries among infants, children, adolescents, and young adults. Am J Dis Child 1990;144:684-91.

7 John SM, Kelly P, Vincent A. Patterns of structural head injury in children younger than 3 years: a ten-year review of 519 patients. J Trauma Acute Care Surg 2013:74:276-81.

8 Pickett W, Streight S, Simpson K, et al. Injuries experienced by infant children: a population-based epidemiological analysis. Pediatrics 2003;111(4 Pt 1):e365-70.

9 Warrington SA, Wright CM, Team AS. Accidents and resulting injuries in premobile infants: data from the ALSPAC study. Arch Dis Child 2001;85:104-7.

10 Ibrahim NG, Wood J, Margulies SS, et al. Influence of age and fall type on head injuries in infants and toddlers. Int I Dev Neurosci 2012;30:201-6.

11 Thompson AK, Bertocci G, Rice W, et al. Pediatric short-distance household falls: biomechanics and associated injury severity. Accid Anal Prev 2011;43:143-50.

12 Reiber GD. Fatal falls in childhood. How far must children fall to sustain fatal head injury? Report of cases and review of the literature. Am J Forensic Med Pathol 1993;14:201-7.

13 Chadwick DL, Bertocci G, Castillo E, et al. Annual risk of death resulting from short falls among young children: less than 1 in 1 million. Pediatrics 2008:121:1213-24.

14 Plunkett J. Fatal pediatric head injuries caused by short-distance falls. Am J Forensic Med Pathol 2001;22:1-12.

15 NICE. Triage, assessment, investigation and early management of head injury in infants, children and adults. National Institute for Health and Clinical Excellence, 2007.
16 European-Union. The Injury Database (IDB) coding manual: data dictionary. Amsterdam, The Netherlands: Consumer Safety Institute, 2005.

17 Trauma ACoSCo. Advanced life support manual. Chicago: American College of Surgeons, 1993.

18 Mackay CA, Burke DP, Burke JA, et al. Association between the assessment of conscious level using the AVPU system and the Glasgow Coma Scale. Pre-Hos Immediate Care 2000;4:17-19.

19 Dietrich AM, Bowman MJ, Ginn-Pease ME, et al. Pediatric head injuries: can clinical factors reliably predict an abnormality on computed tomography? Ann Emerg Med 1993:22:1535-40.

20 Thomas AG, Hegde SV, Dineen RA, et al. Patterns of accidental craniocerebral injury occurring in early childhood. Arch Dis Child 2013;98:787-92.

21 Settle F, Lawrence D, Kummerow M. Pre-ambulatory infants with head trauma: a three-year retrospective study. J Paediatr Child Health 2005;41:130-5.

22 Tarantino CA, Dowd MD, Murdock TC. Short vertical falls in infants. Pediatr Emerg Care 1999;15:5-8.

23 Williams RA. Injuries in infants and small children resulting from witnessed and corroborated free falls. J Trauma 1991:31:1350-2.

24 Chadwick DL, Chin S, Salerno C, et al. Deaths from falls in children: how far is fatal? J Trauma 1991;31:1353-5.

25 Duhaime AC, Alario AJ, Lewander WJ, et al. Head injury in very young children: mechanisms, injury types, and ophthalmologic findings in 100 hospitalized patients younger than 2 years of age. Pediatrics 1992;90(2 Pt 1):179-85.

26 Joffe M, Ludwig S. Stairway injuries in children. Pediatrics 1988;82(3 Pt 2):457-61.

27 Zielinski AE, Rochette LM, Smith GA. Stair-related injuries to young children treated in US emergency departments, 1999-2008. Pediatrics 2012;129:721-7.

28 Osmond MH, Klassen TP, Wells GA, et al. CATCH: a clinical decision rule for the use of computed tomography in children with minor head injury. CMAJ 2010;182:341-8.

29 Dunning J, Daly JP, Lomas JP, et al. Derivation of the children's head injury algorithm for the prediction of important clinical events decision rule for head injury in children. Arch Dis Child 2006:91:885-91. 